\title{
OPTIMIZE DOCUMENT OPERATION USING MOBILE TECHNOLOGY
}

\author{
Horia Demian \\ Management Marketing Department, Faculty of Economics, University of Oradea \\ Ihoriademian@yahoo.com
}

\begin{abstract}
The existence of the standards for transmitting documents in electronic format, which ensure their import without being operated once again in the information system of the client, does not exclude the process of inventory of the goods received for identification, inaccuracies that may occur. This paper present a software solution which has been made for optimizing inventory process by using of bar code scanners on Android devices. For this we have made research on client site to identifying needs, and we have to do research for joining different technology together to achieve the main scope.
\end{abstract}

Keywords: Bar code scanner, Android, mobile systems, document operation.

JEL Classification: $L 86$.

\section{Introduction}

The existence of standards for the transmission of documents in electronic format, which ensure sending them without being operated once again in the customer's information system, does not exclude the process of inventorying the goods received for identification of inaccuracies that may occur. It may happen that for one of the products the quantity received is different from the invoiced quantity, or a particular product has not been received, or has been received from a different assortment. The present paper deals with the optimization of the inventory process within the reception of goods, starting from the practical cases reported by various beneficiaries.

\section{Purposes of the Study and Research Methods}

This paper presents a case study research. We used interviews, during this research, with people from management to understand the main objectives that solution has to be achieved.

The following objectives were set that the IT solution had to achieve:

- Use bar code readers in the process of operating the invoice received from the supplier when it does not arrive in electronic format, with the operation of differences

- The reception of goods on the mobile terminal, it will take place in the real location and not in the accounting office.

- Identification of existing stock for a scanned product as well as display of the sales prices charged for it.

Also, discussions have been made to end users, which results in different changes of the software, according with their direct needs. The main impact of this changes was to minimize the operating time.

This study was driven by design-based research ${ }^{5}$. This research methodology includes four phases: analysis of practical problems, development of solutions, testing and evaluation, reflection and documentation to produce design principles ${ }^{6}$. 


\section{Operating Systems and development environment}

The Android operating system is very well known and widely adopted in mobile telephony occupying today a market share of about $71 \%{ }^{1}$ according to the analysis carried out in the last 12 months. This operating system is also used for devices other than mobile phones, such as tablets, or TVs. Within tablets, we identify a market share of $42 \%{ }^{2}$ for the Android operating system. A special section within mobile terminals is mobile terminals with built-in bar code scanners, which are often found in supermarkets, also known as PDA. Among the operating systems used for PDA, we often meet the version of Windows CE 6.0 whose development was interrupted by Microsoft in 2018, or Windows Mobile 6.5 for which Microsoft announced the interruption of support in 2020. In the case of tablets we will meet Windows 10 which has been optimized for their use (tablet mode).

In our research, prices on the market for tablets with bar code scanner which use Windows or Android operating systems showed us very large price differences between them. The lowest prices are found in the case of tablets with Android operating system. The proportion of these prices being 1 to 5 in certain situations. We have therefore started to develop a mobile solution on the Android operating system, because the cost for final client will be cut off.

We chose to develop a native application due to the benefits they have, compared to other types of applications. These benefits have also been demonstrated in comparing different software development environment where platform specific SDK was choose as the best ${ }^{4}$.

For developing we used Visual Studio C\# with Xamarin libraries, because the same software solutions can easily be translated to iOs and have good libraries for connecting directly to Microsoft Sql Server, without necessity of using web services. In this scenario we can develop a client-server application with the same authentication mechanism as a desktop client-server application. The benefit for using this technique is that we do not have to create another user for mobile application. Operator can use the same user for desktop and mobile application.

The mobile solution has to be integrated to the existing desktop solution was another issue in our development process.

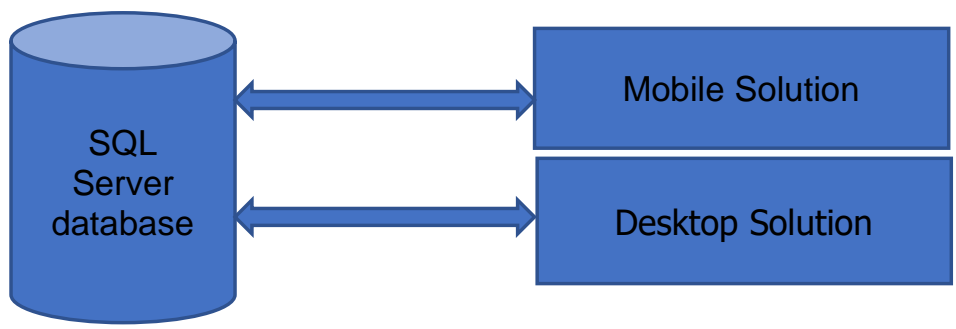

Fig. 1 - Client server architecture for mobile and desktop

\section{Development}

After analyzing the requirements, we identify the following pages which has to contain this solution:

- Login page, used for connecting to the database server

- Home page, from where user can choose what he wants to do 
- Page for looking up of documents

- Header page for invoice/reception

- Detail page used for scanning and operating Quantities and prices which appears in invoice.

- Page for product creation

- Page for searching products

\subsection{Login process}

For login process we wanted that Sql Server check if username and password are correct or not. To do this when the operator writes a username and password, we need to try to open a connection to the database with this credentials. If the username and password are correct, the connection will be made, otherwise operator will receive a message for invalid credentials used. If the credentials are correct, operator will have access to the other options of the applications.

Because the username and password, has to be used in the future, anytime when we will open a connection to the database, these credentials will be memorized as static properties of MainAcitivity class.

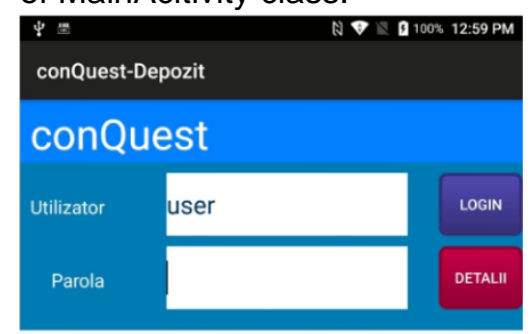

Fig. 2 - Login page

After login process has been successfully made, the user will arise in a main page where he can choose from the available option, what he want to do.

\subsection{Document page in mobile and desktop application}

A document has the following information's: supplier, data, number, currency, total value with VAT and total value of VAT. We have decided to create a page only for this information's because we are limited to the screen resolution as can be seen in fig.3., and we also create a page for recording products, quantity, percentage of VAT used, prices and other properties. 


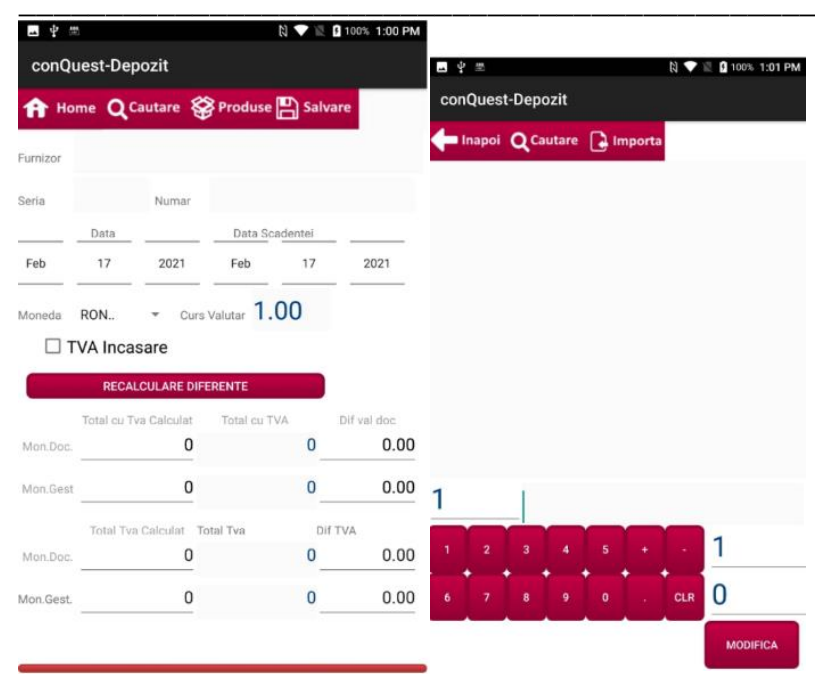

Fig. 3 - Document header and product page

For recording a document, the following action's has to be done. We need to select the supplier, to specify document number and the data, to specify the currency, and to correct if it is necessary the total value with VAT, and the total value of VAT.

In product page we must scan each article. With the help of bar code scanner which is incorporated into device we can easily scan a product, and this product will be automatically recorded in this page. After each scan we can modify the quantity of products, percentage of VAT, and the price according to the invoice or we can go further to the next product.

Because the process of price specification takes time, we were looking for a method to optimize this process. After analyzing a few options, we have decided to implement a strategy for price proposal according to the last buying recorder from the same supplier. This option has speed up scanning process because users have to modify the acquisition price only when differences occurs and not each time.

Another optimization problem was regarding the VAT percentage used for this product. That is why we have decided to use the percentage of VAT recorded for that product. In this scenario also the operator has only to modify VAT percentage only in some particular case and not all the time, so the scanning process can be more fluid.

Stored procedure has been used in SQL Server, for creating methods for looking up to supplier, VAT's, currencies, for recording a new document, for modifying an existing one, for looking up to product specifications, for recording stock movements and so on. These stored procedures were accessed by using different methods inside classes and was called by using connection to database created with user credentials recorded during login process. 


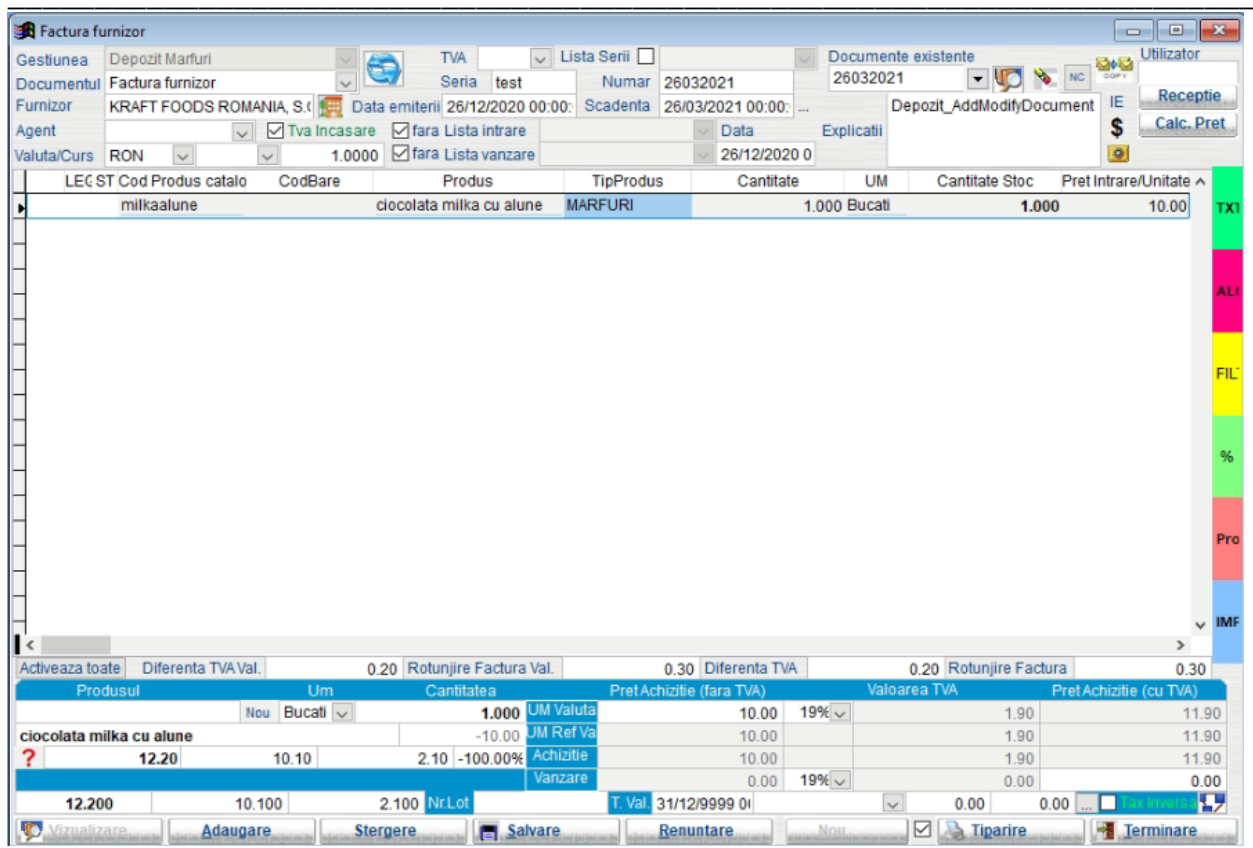

Fig.4 - Document header and product window in desktop

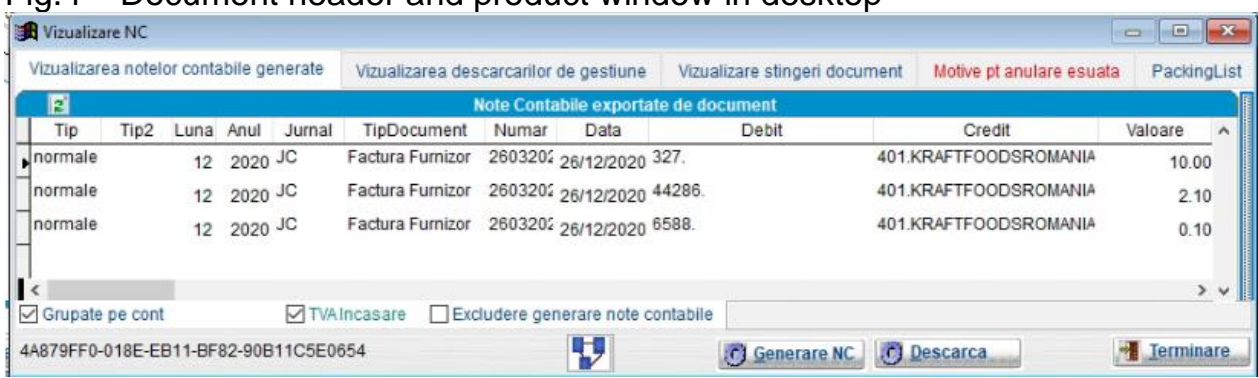

Fig. 5 - Accounting influence of the document recorder with mobile application

\subsection{Performance}

We performed performance tests on the operating time of documents in both the desktop application and the tablet application to find certain problems related to the design of the tablet application. We have made test in two different conditions:

- We scan products without modifying quantities in both applications.

- We scan products and modifying quantities in both applications 


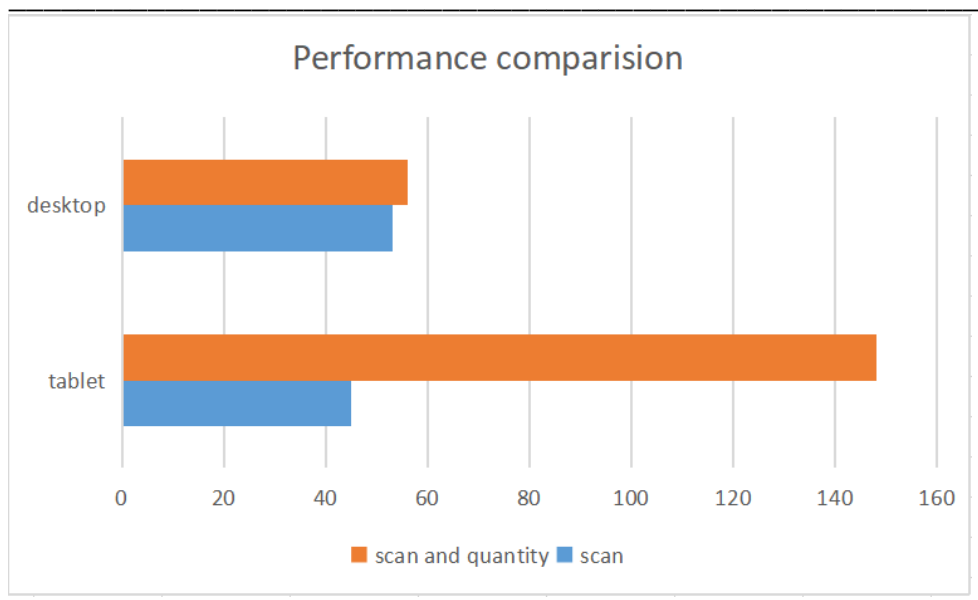

Fig. 6 - Performance comparison

We have identified that in scanning, tablet application is a little bit faster, but we lose a lot of time quantity modification.

\section{Conclusion}

The wide spread of the Android operating system for mobile devices has led to the emergence of terminals with built-in bar code scanners, at reasonable prices that can successfully replace the old PDA.

The computer solution developed also achieves the requirements of operating invoices with correct accounting interpretation (tax rates, reverse taxation, highlighting the differences due to rounding, as well as operating in another currency).

The use of 2D codes by economic operators is not yet widespread, in our case all encoding being 1D.

We must improve quantity modification process in tablet application because of performance issues.

\section{References}

1. https://gs.statcounter.com/os-market-share/mobile/worldwide

2. https://gs.statcounter.com/os-market-share/tablet/worldwide

3. https://docs.microsoft.com/en-us/xamarin/

4. Masi E.,Cantone G.,Calavaro G,Mastrofini M.,Subiaco P - "Mobile Apps Development: A Framework for Technology Decision Making" October 2012, DOI:10.1007/978-3-642-366321_4,Conference: MpbiCase, Volume: 1

5. The Design-Based Research Collective, "Design-Based Research: An Emerging Paradigm for Educational Inquiry"

6. Nilgun Ozdamar Keskin, Abdullah Kuzu, "Development and Testing of a M-Learning System for the Professional Development of Academics Through Design-Based Action Research" - International Review of Research in Open and Distributed Learning Volume 16, Number 1, February 2015. 